\title{
JONNESCO: Um Século de História da Anestesia Raquídea Torácica
}

Em novembro de 2009, fez 100 anos que Thomas Jonnesco publicou seu trabalho intitulado "Analgesia espinal geral' através da punção subaracnóidea na região torácica ${ }^{1}$.

Por meio de estudo com imagem de ressonância magnética (IRM), ficou demonstrado que existe grande distância entre as meníngeas e a medula espinal ${ }^{2}$. Este estudo foi realizado com 16 pacientes mostrando que existe um espaço onde se pode colocar uma agulha com segurança e realizar anestesia raquídea torácicas, sendo que a maior distância encontrada foi na altura da 5a vértebra torácica $( \pm 5 \mathrm{~mm})$. No passado, a mielografia subaracnóidea, realizada por neurologistas e neurorradiologistas, foi bastante utilizada através da punção torácica e cervical ${ }^{3} \mathrm{e}$ imediatamente aceita como uma alternativa em relação à punção lombar ${ }^{4}$. Este procedimento é geralmente considerado seguro, mas, ocasionalmente, foi notada "sensação elétrica" causada pela penetração da agulha na medula espinal, porém sem relatarem complicações resultantes ${ }^{5}$. Interessante é que, com o advento da IRM a mielografia subaracnóidea continua sendo realizada com algumas indicações ${ }^{6}$. Contudo, entre os anestesiologistas, ainda persiste o receio do risco de lesão direta da medula espinal com a punção do espaço subaracnóideo acima da 1 a vértebra lombar.

Em 1909, Thomas Jonnesco ${ }^{1}$ propôs a realização de anestesia raquídea geral para cirurgias de crânio, cabeça, pescoço e tórax. Ele realizava punção entre a $1^{\underline{a}}$ e a $2^{\underline{a}}$ vértebras torácicas, a qual produzia uma perfeita e profunda analgesia para o segmento do corpo compreendendo cabeça, pescoço e membros superiores. Como a punção torácica média entre a 7a e a 8a vértebras era mais difícil de realizar e desnecessária para cirurgias do segmento torácico baixo, ele realizava a punção entre a 12a vértebra torácica e a 1a vértebra lombar, a qual era facilmente realizada e produzia anestesia para a parte inferior do corpo.

Em 1954, Frumin e col. ${ }^{7}$ propõem a realização de anestesia raquídea segmentar por punção torácica baixa. O grupo estudou a anestesia raquídea segmentar em 10 pacientes, por punção lombar e colocação de cateter radiopaco no espaço subaracnóideo até atingir a 12a vértebra torácica. Com o paciente em decúbito dorsal injetava-se procaína a 5\% através do cateter em 3 segundos, obtendo bloqueio torácico baixo e lombar superior em nove de 10 pacientes.

Em 2006, começa a nova era de estudos da anestesia raquídea na região torácica buscando a segurança total. Van Zundert e col. ${ }^{8}$ propuseram a realização de anestesia raquídea segmentar para colecistectomia videolaparoscópica em paciente com grave doença pulmonar obstrutiva, por punção torácica baixa $\left(\mathrm{T}_{10}\right)$ através do bloqueio combinado raqui-peridural. No ano seguinte ${ }^{9}$, o mesmo grupo demonstra que a anestesia raquídea segmentar por punção, da mesma forma descrita no trabalho anterior ${ }^{8}$, pode ser usada com segurança em pacientes saudáveis submetidos à colecistectomia videolaparoscópica. Diferentemente de van Zundert e col. ${ }^{8,9}$ que utilizaram a agulha ponta de lápis para realização de anestesia raquídea torácica, aqui no Brasil foi utilizada aguIha cortante do tipo Quincke, por apresentar orifício terminal 10. O orifício da agulha ponta de lápis está a $0,8 \mathrm{~mm}$ da sua ponta, sendo dessa forma necessária introdução de mais de $2 \mathrm{~mm}$ no espaço subaracnóideo para se ter certeza que todo o orifício esteja dentro do canal vertebral e se obtenha o líquido cefalorraquidiano (LCR) ${ }^{11}$. Em relação à segurança das agulhas ponta de lápis, Turner e Shaw ${ }^{12}$ foram os primeiros a chamar atenção, pois descreveram uma alta incidência de parestesia. Isso é verdade com as agulhas ponta de lápis, também chamadas atraumáticas, pois há necessidade de se introduzir até $1 \mathrm{~mm}$ da sua ponta cega para o aparecimento de LCR, o que não é necessário com a agulha tipo Quincke. Com agulhas com bisel cortante, imediatamente após sua penetração na dura-máter aparece líquido cefalorraquidiano.

A agulha ponta de lápis, usualmente a 25G e 27G Whitacre, foi utilizada em todos os sete casos descritos com dano neurológico após anestesia raquídea ou bloqueio combinado raqui-peridural ${ }^{13}$. Estudo in vitro com microscopia eletrônica de varredura mostrou que a agulha ponta de lápis causa maior lesão nas membranas do que a ponta cortante ${ }^{14}$. O orifício deixado pela agulha ponta de lápis provavelmente causa menor perda de LCR, porém o dano pode ser maior quando em contato com tecido espinal.

No Brasil, não existem dados para afirmar qual a agulha mais utilizada. Sem um bom estudo comparativo, é impossível dizer qual a agulha está mais associada a lesões da medula espinal, porém alguns dados indicam ser a agulha ponta de lápis. Alta incidência de parestesia (12\%) foi notada com agulha ponta de lápis comparada com a cortante ${ }^{15}$, e $26,6 \%$ com o bloqueio combinado raqui-peridural ${ }^{16}$, números maiores do que os relatados com agulhas cortantes.

Em 1909, Jonnesco escreveu 1: "A agulha que prefiro tem uma ponta meio quadrada, pois uma vez que o espaço aracnoide é relativamente pequeno, se a ponta da agulha é oblíqua, é possível que parte do orifício entre na dura-máter enquanto o resto fica do lado de fora". Visão fantástica, ele não apenas usava a anestesia raquídea torácica como preferia a agulha com ponta cortante. As histórias descritas em todos os pacientes em que foram usadas agulhas ponta de lápis, com lesão de mais de uma raiz, sugerem fortemente que a ponta da agulha sozinha pode causar lesão ao cone medular. Dessa forma, estudos comparando as agulhas do mercado são importantes nesse momento em que a anestesia raquídea torácica começa a ser cientificamente bem desenvolvida. 


\section{REFERÊNCIAS / REFERENCES}

01. Jonnesco T. General spinal analgesia. Br Med J 1909;2:1396-1401.

02. Imbelloni LE, Ferraz-Filho JR, Quirici MB et al - Magnetic resonance imaging of the spinal column. Br J Anaesth. 2008;101:433-434.

03. Robertson HJ, Smith RD - Cervical myelography: Survey of modes of practice and major complications. Neuroradiology, 1990;174:79-83.

04. Orrison WW, Eldervik OP, Sacket JF - Lateral C1-2 puncture for cervical myelography, III. Historical, anatomic, and technical considerations. Radiology 1983;146:401-408.

05. Heinz ER, Goldman RL - The role of gas myelography in neuroradiologic dianosis. Radiology 1972;102:629-634.

06. Sandow BA, Donnal JF - Myelography complications and current practice patterns. AJR 2005;185:768-771.

07. Frumin MJ, Schwartz H, Burns J et al. - Dorsal root ganglion blockade during threshold segmental spinal anesthesia in man. J Pharm Exp Ther, 1954;112:387-392.

08. van Zundert AAJ, Stultiens G, Jakimowicz JJ et al. - Segmental spinal anaesthesia for cholecystectomy in a patient with severe lung disease. Br J Anaesth, 2006;96:464-466.

09. van Zundert AAJ, Stultiens G, Jakimowicz JJ et al. - Laparoscopic cholecystectomy under segmental thoracic spinal anaesthesia: a feasibility study. Br J Anaesth, 2007;98:682-686.
10. Imbelloni LE, Fornasari M, Fialho JC. - Uso do bloqueio combinado raqui-peridural durante cirurgia de cólon em paciente de alto risco. Relato de Caso. Rev Bras Anestesiol, 2009;59:741-745.

11. Krommendijk EJ, Verheinjen R, van Dijk B et al. - The pencan 25-gauge needle: A new pencil-point for spinal anesthesia tested in 1,193 patients. Reg Anesth Pain Med, 1999:24:43-50.

12. Turner MA, Shaw M. - Atraumatic spinal needles. Anaesthesia, 1993;48:452.

13. Reynolds, F. - Damage to the conus medullaris following spinal anaesthesia. Anaesthesia, 2001;56:238-47.

14. Reina MA, de Leon-Casasola OA, Lopez A et al. - An in vitro study of dural lesions produced by 25-gauge Quincke and Whitacre needles evaluated by scanning electron microscopy. Reg Anesth Pain Med, 2000;25:393-402.

15. Hopkinson JM, Samaan AK, Russell IF et al. - A comparative multicentre trial of spinal needles for caesarean section. Anaesthesia, 1997;52:998-1014.

16. Turner MA, Reifenberg NA - Combined spinal epidural anaesthesia. The single space double-barrel technique. Int J Obstet Anesth, 1995;4:158-160. 